\title{
A High-fidelity Multiphysics Model for the New Solid Oxide Iron-Air Redox Battery
}

\section{Part I: Bridging Mass Transport and Charge Transfer with Redox Cycle Kinetics}

\author{
Xinfang Jin, Xuan Zhao and Kevin Huang * \\ Department of Mechanical Engineering, University of South Carolina, Columbia, SC 29201, \\ USA. Tel: 1-803-777-0204, Fax: 1-803-777-0106 Email: $\underline{\text { Huang46@ cec.sc.edu. }}$
}

A high-fidelity two-dimensional axial symmetrical multi-physics model is described in this paper as an effort to simulate the cycle performance of a recently discovered solid oxide metal-air redox battery (SOMARB). The model collectively considers mass transport, charge transfer and chemical redox cycle kinetics occurring across the components of the battery, and is validated by experimental data obtained from independent research. In particular, the redox kinetics at the energy storage unit is well represented by Johnson-Mehl-Avrami-Kolmogorov (JMAK) and Shrinking Core models. The results explicitly show that the reduction of $\mathrm{Fe}_{3} \mathrm{O}_{4}$ during the charging cycle limits the overall performance. Distributions of electrode potential, overpotential, Nernst potential, and $\mathrm{H}_{2} / \mathrm{H}_{2} \mathrm{O}$-concentration across various components of the battery are also systematically investigated.

KEYWORDS: energy storage; solid oxide fuel cell; battery; redox cycle; modeling 


\section{Introduction}

Most electricity in the United States is generated at power plants that run on coal and natural gas

- fossil fuels that contribute significantly to global warming and climate change by emitting large amounts of $\mathrm{CO}_{2}$. Renewable energy from emission-free sources such as solar and wind holds the promise of reducing $\mathrm{CO}_{2}$ emissions. But the solar and wind power generation is not constant; there are times when solar and wind farms generate more electricity than is needed by consumers, inevitably resulting in unbalanced energy flow and inefficiency. Storing the surplus energy on the electrical grid in batteries for later use is the solution. A wide variety of battery technologies have been developed for this purpose in the past, but none of them is currently ready for large-scale commercial implementation. Development of advanced battery technologies for renewable and grid storage is, therefore, imperative.

As an effort to address the lack of grid-scale storage, a new class of rechargeable battery composed of a reversible solid oxide fuel cell (RSOFC) and a metal-metal oxide redox cycle unit (RCU), termed solid oxide metal-air redox battery or SOMARB, has recently been developed by our group [1]. Its high energy-density, high rate-capacity and easy system integration has drawn an increasing interest from the energy community. Since its debut in 2011, significant progress has been made in the areas of electrical performance [1-4], new metal-air chemistries [5-7] and operation optimization [8-10].

Compared to the fruitful experimental investigations, mathematical modeling of the multiphysicochemical processes occurring in the SOMARB lags behind. Ohmoti et al [11] first reported a 1D diffusion model to describe the effect of gas diffusion on the charge/discharge characteristics, and further extended the model with the addition of heat transfer to a $2 \mathrm{D}$ domain 
to study the effect of temperature [12]. Clearly, use of Fick's diffusion law to describe the gas diffusion process within the porous RCU medium is too simplistic. A more rigorous $2 \mathrm{D}$ multiphysics model proposed by Guo et al [13] considered mass and momentum transport by Maxwell-Stefan equation, from which the discharge behavior at high current density was simulated to match well with the experimental results. However, the model only considered RSOFC as a boundary condition, neglecting the effect of the performance of RSOFC on the overall performance of the SOMARB battery. Moreover, none of the two models took into the consideration of time-dependent kinetics of redox reactions occurring in the RCU. This would undoubtedly misrepresent the true behavior of the SOMARB as the redox kinetics in the RCU plays an important role in the performance of the battery.

In this study, we demonstrate a high-fidelity multiphysics model collectively considering electrochemical charge transfer, mass transport and time-dependent oxidation/reduction kinetics. The parameters used in the model were directly validated with the experimental data obtained from the V-I curve of RSOFC and discharge/charge characteristic of the battery.

\section{The Mathematical Model}

The mathematical model is constructed from the configuration of SOMARB shown in Fig. $1 ; \mathrm{Fe}$ is used as the RCU material, the battery is hereinafter referred to as solid oxide iron-air redox battery or SOIARB. Different from the previous modeling[13], the operating temperature of interest for this study is $550^{\circ} \mathrm{C}$, at which $\mathrm{Fe} / \mathrm{Fe}_{3} \mathrm{O}_{4}$ is the prevalent redox couple in the RCU. The RCU bed is enclosed in the anode chamber of an electrolyte-supported RSOFC filled with an oxygen shuttle gas $\mathrm{H}_{2}-\mathrm{H}_{2} \mathrm{O}$. The cathode is constantly open to air. 
The dual fuel-cell and electrolyzer modes offered by RSOFC constitute the discharge and charge cycle, respectively, of the battery. During the discharge cycle, RSOFC electrochemically consumes $\mathrm{H}_{2}$ to produce $\mathrm{H}_{2} \mathrm{O}$ and electricity, while $\mathrm{Fe}$ is being oxidized by $\mathrm{H}_{2} \mathrm{O}$ produced to form $\mathrm{Fe}_{3} \mathrm{O}_{4}$ and $\mathrm{H}_{2}$ to sustain the electrochemical oxidation. During the charge cycle, RSOFC electrochemically splits $\mathrm{H}_{2} \mathrm{O}$ into $\mathrm{H}_{2}$ with external electrical energy supply, while $\mathrm{Fe}_{3} \mathrm{O}_{4}$ is being reduced back to Fe with $\mathrm{H}_{2}$ produced and to form $\mathrm{H}_{2} \mathrm{O}$ to sustain the electrolysis process. During the cycles, $\mathrm{H}_{2}$ and $\mathrm{H}_{2} \mathrm{O}$ in the chamber constantly diffuse back-and-forth between the RSOFC and $\mathrm{RCU}$ bed, and maintain a dynamic equilibrium with the $\mathrm{Fe} / \mathrm{Fe}_{3} \mathrm{O}_{4}$ redox couple. The reactions occurring in RSOFC and RCU can be generalized by:

$$
\begin{aligned}
& \mathrm{O}_{2} \text {-electrode of RSOFC: } \frac{1}{2} \mathrm{O}_{2}(\mathrm{~g})+2 e^{-} \underset{\text { charge }}{\stackrel{\text { discharge }}{\rightleftharpoons}} O^{2-} \\
& \mathrm{H}_{2} \text {-electrode of RSOFC: } \mathrm{H}_{2}(\mathrm{~g})+\mathrm{O}^{2-} \underset{\text { charge }}{\stackrel{\text { discharge }}{\rightleftharpoons}} \mathrm{H}_{2} \mathrm{O}(\mathrm{g})+2 e^{-} \\
& \text {RCU: } 4 \mathrm{H}_{2} \mathrm{O}(\mathrm{g})+3 \mathrm{Fe} \underset{\text { charge }}{\stackrel{\text { discharge }}{\text { charg }}} \mathrm{Fe}_{3} \mathrm{O}_{4}+4 \mathrm{H}_{2}(\mathrm{~g})
\end{aligned}
$$

It is evident that an SOIARB involves multiple physicochemical processes, including electron and oxygen-ion transport in RSOFC, electrochemical reactions at triple phase boundaries of RSOFC electrodes, gas diffusion through porous electrodes of RSOFC, gas diffusion through open space (chamber) between anode and RCU, gas diffusion through porous RCU bed, and more importantly, chemically driven redox reactions occurring inside the RCU. In the following sections, the corresponding mathematical governing equations will be discussed in details.

\subsection{Charge conservation in RSOFC}


There are two charged species, viz. electrons and oxide-ions, transporting in porous electrodes of an RSOFC, while only oxide-ions are allowed to migrate through the dense electrolyte. The charge conservation of both species are governed by Ohm's law,

$$
\begin{aligned}
& \nabla \cdot\left(-\sigma_{e, o / h} \nabla \phi_{e}\right)= \pm S_{a, o / h} i_{i c t, o / h} \\
& \nabla \cdot\left(-\sigma_{i, o / h} \nabla \phi_{i}\right)=\mp S_{a, o / h} i_{i c t, o / h} \\
& \nabla \cdot\left(-\sigma_{i, e l} \nabla \phi_{i}\right)=0
\end{aligned}
$$

Here the subscripts $e$ and $i$ represent electronic and ionic species; $o / h$ represents the oxygen electrode/hydrogen electrode domain; $e l$ stands for the electrolyte domain; $S_{a}$ is the active area per unit volume, $\left(\mathrm{m}^{-1}\right)$, of electrochemical reaction; $i_{i c t}$ is the local charge transfer current density. The signs of the source terms in eqs.(4) and (5) correspond to the RSOFC operating mode. For the SOFC mode, $\mathrm{O}_{2}$-electrode consumes electrons to produce oxide-ions, while $\mathrm{H}_{2}$-electrode generates electrons by reducing oxide-ion. For the electrolysis mode, all the electrochemical reactions occur in the reverse direction.

The $i_{i c t}$ in eqs. (4) and (5) can be calculated using Bulter-Volmer equation [14]:

$$
i_{\text {ict }}=i_{0}\left(\frac{c_{\text {react }}}{c_{\text {react }}^{0}} \exp \left(\frac{0.5 F}{R T} \eta\right)-\frac{c_{\text {prod }}}{c_{\text {prod }}^{0}} \exp \left(-\frac{0.5 F}{R T} \eta\right)\right)
$$

Here $i_{0}$ is the exchange current density $\left(\mathrm{A} \cdot \mathrm{m}^{-2}\right), F$ is the Faraday constant $96485\left(\mathrm{C} \cdot \mathrm{mol}^{-1}\right), R$ is the gas constant $8.314 \mathrm{~J} \cdot\left(\mathrm{mol}^{-1} \cdot \mathrm{K}^{-1}\right) . c_{\text {react }}, c_{\text {react }}^{0}, c_{\text {prod }}, c_{\text {prod }}^{0}$ are the reactant and product concentrations at the reaction active sites and the electrode/gas supply interface, respectively. $\eta$ is the local overpotential $(\mathrm{V})$, defined as 


$$
\eta=\phi_{e}-\phi_{i}-\Delta \phi_{e q}
$$

where $\Delta \phi_{e q}$ is the equilibrium potential difference. If hydrogen electrode is set as a reference electrode with the ground voltage, $\Delta \phi_{e q, o}, \Delta \phi_{e q}$ at $\mathrm{O}_{2}$-electrode, can be represented by:

$$
\Delta \phi_{e q, o}=E^{0}-\frac{R T}{2 F} \ln \left(\frac{p_{\mathrm{H}_{2} O, h}}{p_{O_{2, o}}^{0.5} p_{H_{2, h}}}\right)
$$

where $p$ represents the partial pressure of gas species $\mathrm{O}_{2}, \mathrm{H}_{2}$ and $\mathrm{H}_{2} \mathrm{O}$, respectively, $E^{0}$ is the Nernst potential under the standard state and can be calculated from,

$$
E^{0}=-\frac{\Delta G^{0}}{2 F}
$$

where $\Delta G^{0}$ is the change of standard-state Gibbs free energy between the products and the reactants. For, example, under the operating condition of $\mathrm{T}=823.15 \mathrm{~K}, p_{O_{2, o}}=0.21 \mathrm{~atm}, p_{H_{2, h}}=$ $0.97 \mathrm{~atm}, p_{\mathrm{H}_{2} \mathrm{O}, \mathrm{h}}=0.03 \mathrm{~atm}, E^{0}=1.048 \mathrm{~V}$, resulting in a $\Delta \phi_{e q, o}=1.1438 \mathrm{~V}$.

\subsection{Gas species transport}

As is implicated from Fig.1, the multi-component mass transport occurs in the whole computational domain except the dense electrolyte of RSOFC. Maxwell-Stefan's equation is employed to calculate the concentration distribution of individual species in such a multicomponent transport:

$$
\nabla\left(-\rho \omega_{i} \sum_{j=1}^{n} D_{i j}^{e f f}\left(\frac{M}{M_{j}}\left(\nabla \omega_{j}+\omega_{j} \frac{\nabla M}{M_{j}}\right)\right)\right)=R_{i}
$$

Here $\rho$ is the density of gas; $\omega_{i j}$ the mass fraction of species $i / j ; M_{j}$ is the molecular weight of species $j ; M=\sum_{j=1}^{n} x_{j} M_{j}$ is the average molecular weight; $x_{j}$ is the molar fraction of species $j$; 
$R_{i}= \pm \frac{i_{c t} S_{a} M_{i}}{n_{i} F}$, is the source term related to the exchange current density in eq.(7); $D_{i j}^{e f f}$ is the effective binary diffusion coefficient. In the gas chamber between RSOFC and RCU, $D_{i j}^{e f f}$ equals the binary diffusion coefficient for species $i$ and $j$, and is defined as a function of temperature $T$ and pressure $p$ by

$$
D_{i j}=k \frac{T^{1.75}}{p\left(v_{i}^{1 / 3}+v_{j}^{1 / 3}\right)^{2}}\left[\frac{1}{M_{i}}+\frac{1}{M_{j}}\right]^{1 / 2}
$$

where $k$ is the reference diffusivity $\left(\mathrm{m}^{2} \cdot \mathrm{s}^{-1}\right), v_{i}$ is the kinetic volume of species $i$.

In the porous electrodes or RCU bed, both Knudsen diffusion and free molecular diffusion mechanisms can be involved in the process. To avoid violation of species conservation, the average Bosanquet diffusion coefficient is employed[15],

$$
D_{i j}^{e f f}=\frac{1}{2} \frac{\varepsilon}{\tau}\left(\frac{1}{\frac{1}{D_{i j}}+\frac{1}{D_{K n, i}}}+\frac{1}{\frac{1}{D_{i j}}+\frac{1}{D_{K n, j}}}\right)
$$

Here $D_{i j}$ is the binary diffusion coefficient; $D_{K n, i}$ is the Knudsen diffusion coefficient for species $i[16] ; \varepsilon$ and $\tau$ are porosity and tortuosity of the porous medium, respectively.

Knudsen diffusion coefficient depends on the pore radius $d_{\text {pore }}$ :

$$
D_{K n, i}=\frac{97}{2} d_{\text {pore }} \sqrt{T / M_{i}}
$$

with $d_{\text {pore }}=\frac{2}{3} \frac{\varepsilon d_{p}}{1-\varepsilon}$ being the diameter of spherical particle of the porous medium; $d_{p}$ is the pore radius of the porous medium.

\subsection{Reaction kinetics model for RCU}


The chemically-driven reversible reaction occurring in the RCU, eq.(3), proceed in opposite directions under the two operating modes:

$$
4 \mathrm{H}_{2} \mathrm{O}(\mathrm{g})+3 \mathrm{Fe}(\mathrm{s}) \underset{\mathrm{kb}}{\stackrel{\mathrm{kf}}{\rightleftharpoons}} \mathrm{Fe}_{3} \mathrm{O}_{4}(s)+4 \mathrm{H}_{2}(g)
$$

where $k_{f}$ represents the reaction rate for the forward reaction (discharge cycle) and $k_{b}$ as the rate for the backward reaction (charge cycle). We assume that both the forward and backward reactions are elementary. As $\mathrm{H}_{2} \mathrm{O}$ and $\mathrm{H}_{2}$ are in gas phase and $\mathrm{Fe}$ and $\mathrm{Fe}_{3} \mathrm{O}_{4}$ are in solid phase, the activities of $\mathrm{H}_{2}$ and $\mathrm{H}_{2} \mathrm{O}$ are represented by their partial pressures, whereas the activities of $\mathrm{Fe}$ and $\mathrm{Fe}_{3} \mathrm{O}_{4}$ are one. According to the reaction rate law, the rate of consumption/production of $\mathrm{H}_{2} \mathrm{O}, r_{\mathrm{H}_{2} \mathrm{O}}$, can be expressed by:

$$
r_{\mathrm{H}_{2} \mathrm{O}}=k_{f} x_{\mathrm{H}_{2} \mathrm{O}}^{4}-k_{b} x_{\mathrm{H}_{2}}^{4}
$$

At equilibrium, the net rate of reaction is zero for all species involved in the reaction, leading to

$$
\frac{k_{f}}{k_{b}}=\frac{x_{H_{2}}^{4}}{x_{H_{2} O}^{4} O}
$$

Since the equilibrium constant $\mathrm{K}$ of reaction (15) equals

$$
K=\frac{x_{H_{2}}^{4}}{x_{H_{2}}^{4} \mathrm{O}}
$$

Combining with the standard free energy change, $\Delta \mathrm{G}^{0}$, leads to

$$
K=\exp \left(-\frac{\Delta G^{o}}{R T}\right)=\frac{x_{H_{2}}^{4}}{x_{H_{2} O}^{4}}
$$


Under the operating condition of $\mathrm{T}=823.15 \mathrm{~K}, \Delta G^{o}=-35.712 K J, K=\frac{x_{\mathrm{H}_{2}}^{4}}{x_{\mathrm{H}_{2} \mathrm{O}}}=\frac{k_{f}}{k_{b}}=185$, $x_{\mathrm{H}_{2} \mathrm{O}}: x_{\mathrm{H}_{2}}=0.21: 0.79$.

In the literature, the oxidation kinetics of Fe has been well described by the JMAK model[1720], where effects of the geometry of a solid-phase particle and the structure of a porous media are lump-summed into the fraction of solid material reacted. The reduction kinetics of $\mathrm{Fe}_{3} \mathrm{O}_{4}$ has been commonly described by the Shrinking Core model [21-27]. In the following, the details of these two models will be discussed.

\subsection{1 "Shrinking Core" model [27]}

Shrinking Core model is generally used to describe the relationship between the kinetic rate and reacted fraction of a solid phase during a reduction process. The model assumes that the solid phase is composed of $\mathrm{Fe}_{3} \mathrm{O}_{4}$ particles in uniform sizes. As the reduction reaction proceeds, a porous layer of $\mathrm{Fe}$ is created on the surface. The thickness of the Fe grows with time. Fig.2 shows a schematic of the Shrinking Core model. We assume that the particle radius is $R_{c 0}$ and remains constant during reduction, while the unreacted core shrinks with time.

There are five distinct steps involved in the reduction reaction: 1) diffusion of $\mathrm{H}_{2}$ from bulk phase to the shell surface (diffusion through the surface boundary layer); 2) diffusion of $\mathrm{H}_{2}$ from the shell surface to the core surface (diffusion through the Fe porous layer); 3) reaction on the surface of the core to form $\mathrm{Fe}$ and $\mathrm{H}_{2} \mathrm{O} ; 4$ ) diffusion of $\mathrm{H}_{2} \mathrm{O}$ from the core surface to the shell surface (diffusion through $\mathrm{Fe}$ porous layer); 5) diffusion of $\mathrm{H}_{2} \mathrm{O}$ from the shell surface to bulk gas (diffusion through surface boundary layer). Assuming that the surface reaction of Step-3 is rate limiting, the rate of $\mathrm{H}_{2}$ consumption can be expressed by: 


$$
\frac{d N_{H_{2}}}{d t}=4 \pi r_{c}^{2} \rho_{g}\left(k_{f} x_{H_{2} O}^{4}-k_{b} x_{H_{2}}^{4}\right)
$$

Similarly, the consumption rate of $\mathrm{Fe}_{3} \mathrm{O}_{4}$ can be expressed by:

$$
\frac{d N_{F e_{3} O_{4}}}{d t}=4 \pi r_{c}^{2} \rho_{\mathrm{Fe}_{3} O_{4}} \frac{d r_{c}}{d t}
$$

From eq.(3), $\frac{d N_{\mathrm{H}_{2}}}{4 d t}=\frac{d N_{\mathrm{Fe}_{3} \mathrm{O}_{4}}}{d t}$, it leads to

$$
\frac{d r_{c}}{d t}=\frac{\rho_{g}\left(k_{f} x_{\mathrm{H}_{2} \mathrm{O}}^{4}-k_{b} x_{\mathrm{H}_{2}}^{4}\right)}{4 \rho_{\mathrm{Fe}_{3} \mathrm{O}_{4}}}
$$

The fraction of reacted $\mathrm{Fe}_{3} \mathrm{O}_{4}, x_{\mathrm{Fe}_{3} \mathrm{O}_{4}}$, is related to $r_{c}$ by:

$$
1-x_{\mathrm{Fe}_{3} \mathrm{O}_{4}}=\left(\frac{r_{c}}{R_{c 0}}\right)^{3}
$$

Substitution of $r_{c}$ in eq.(23) into eq.(22) yields

$$
\frac{d x_{F_{3} O_{3}}}{d t}=\frac{3 \rho_{g}\left(k_{f} x_{H_{2} O}^{4}-k_{b} x_{H_{2}}^{4}\right)}{4 \rho_{F e_{3} O_{4}} R_{c 0}}\left(1-x_{F_{3} O_{4}}\right)^{\frac{2}{3}}
$$

This equation has been consistently used throughout our model for calculating the reduction kinetics during the charge cycle.

\subsection{2 “JMAK” model [20]}

The Johnson-Mehl-Avrami Kolmogorov (JMAK) theory is commonly used in the literature to describe the kinetics of solid-state transformation. The derivation of the JMAK model is based on the combination of three processes: nucleation, growth and impingement of randomly distributed nuclei. According to the model, the fraction of solid material (here Fe) reacted, $x_{F e}$, as a function of time at a constant temperature is given by: 


$$
x_{F e}=1-\exp \left[-\left(k_{o} t\right)^{N}\right]
$$

Differentiating eq.(25) yields

$$
\frac{d x_{F e}}{d t}=k_{o} N\left(1-x_{F e}\right)\left[-\ln \left(1-x_{F e}\right)\right]^{1-\frac{1}{N}}
$$

Here $N$ is the Avrami exponent, an indicative of the nature of the transformation process; $k_{o}$ is the global oxidation rate constant which depends on both nucleation and growth processes. As the solid Fe is presented as a porous structure, the chemical reaction rate must also correlated with the molar fraction (or partial pressure) of the gas phase. We, therefore, introduce eq.(27) as the new governing equation to describe the oxidation kinetics of Fe in the RCU throughout our modeling:

$$
\frac{d x_{F e}}{d t}=\left(k_{f} x_{H_{2} O}^{4}-k_{b} x_{H_{2}}^{4}\right) N\left(1-x_{F e}\right)\left[-\ln \left(1-x_{F e}\right)\right]^{1-\frac{1}{N}}
$$

Here $x_{\mathrm{H}_{2} \mathrm{O}}$ and $x_{\mathrm{H}_{2}}$ are the molar fractions of $\mathrm{H}_{2} \mathrm{O}$ and $\mathrm{H}_{2}$, respectively.

It is worth mentioning that both "Shrinking Core" and "JMAK" models are phenomenological but mechanistic in nature. Therefore, the simulations presented in this study are carried out on a macro-scale with volume averaged properties.

\section{Construction of model with boundary/initial conditions}

There are three components considered in the model: a RSOFC, a free space (chamber) filled with $\mathrm{H}_{2}$ and $\mathrm{H}_{2} \mathrm{O}$ and a RCU bed. Fig. 3 shows the actual dimensions of each component. The button-type RSOFC is consisted of a $180-\mu$ m thick $\mathrm{La}_{0.8} \mathrm{Sr}_{0.2} \mathrm{Ga}_{0.83} \mathrm{Mg}_{0.17} \mathrm{O}_{3-\delta}$ (LSGM) electrolyte 
membrane, a $30-\mu \mathrm{m}$ thick $\mathrm{Ce}_{0.8} \mathrm{Gd}_{0.2} \mathrm{O}_{2-\delta} / \mathrm{Ni}$ composite $\mathrm{H}_{2}$-electrode, and a $50-\mu \mathrm{m}$ $\mathrm{Sm}_{0.5} \mathrm{Sr}_{0.5} \mathrm{CoO}_{3-\delta} / \mathrm{Sm}_{0.2} \mathrm{Ce}_{0.8} \mathrm{O}_{1.9}$ composite $\mathrm{O}_{2}$-electrode. The $\mathrm{RCU}$ is made of nanostructured porous $\mathrm{Fe}-\mathrm{Fe}_{3} \mathrm{O}_{4}$ pellets synthesized from carbothermic reaction [8]. The whole system is operated under an isothermal condition. The convective mass transfer of concentrated species is neglected due to the fact that it is a closed stationary system.

In order to solve the coupled partial differential equations (PDEs) of the charge and mass balance, the conditions of all outer interfaces are specified in Table 1 . Since the model is transient in nature, the initial conditions are very important to solving the PDEs, especially the interdiffusion of $\mathrm{H}_{2}$ and $\mathrm{H}_{2} \mathrm{O}$, which needs to be balanced between RSOFC and RCU as reactions occur in such a closed system. According to the experiments, the initial gas composition in the chamber was taken as $\mathrm{H}_{2}: \mathrm{H}_{2} \mathrm{O}=0.97: 0.03$.

The initial condition for the reacted molar fraction of $\mathrm{Fe}$ is set to $x_{F e, 0}=10^{-5}$ (a very small number for calculation purpose), and as the discharge cycle (or oxidation reaction) proceeds, the fraction of reacted iron increases. The end condition for the reacted Fe is taken as $x_{F e, f}=0.6$ when the battery is switched to the charge mode; it also becomes the initial condition for the reacted molar fraction of $\mathrm{Fe}_{3} \mathrm{O}_{4}$ for the charge cycle. During the discharge/charge cycle, the mass ratio between $\mathrm{Fe}$ and $\mathrm{Fe}_{3} \mathrm{O}_{4}$ varies with time, which further introduces changes in molar volume and porosity $(\varepsilon)$ in the RCU bed. The relation among $\varepsilon, x_{F e}$ and $x_{\mathrm{Fe}_{3} \mathrm{O}_{4}}$ is given as follows:

$$
\varepsilon=\varepsilon_{0}+\left(1-\varepsilon_{0}\right) x_{F e}\left(1-x_{F_{3} O_{4}}\right) c_{F e}\left(\frac{M_{F e}}{\rho_{F e}}-\frac{1}{3} \frac{M_{F_{3} O_{4}}}{\rho_{F e_{3} O_{4}}}\right)
$$

where $\varepsilon_{0}$ is the initial porosity of RCU bed, $M_{F e}, \rho_{F e}$ and $M_{\mathrm{Fe}_{3} \mathrm{O}_{4}}, \rho_{\mathrm{Fe}_{3} \mathrm{O}_{4}}$ are the molar mass and density of $\mathrm{Fe}$ and $\mathrm{Fe}_{3} \mathrm{O}_{4}$, respectively. $c_{F e}=\frac{\rho_{F e}}{M_{F e}}$ is the molar concentration of $\mathrm{Fe}$. 


\section{Numerical solution and validation}

By combining eqs. (4), (5), (6), (11), (24) and (27), the electronic potential $\phi_{e}$ and ionic potential $\phi_{i}$, mass fraction of gas species, $\omega_{j}$, the reacted fraction ratio $x_{\mathrm{Fe}} / x_{\mathrm{Fe}_{3} \mathrm{O}_{4}}$ can be solved as a function of time. The boundary conditions and input parameters used for the solutions are listed in Table 1 and Table 2, respectively. The computation was carried out using a commercial software package of COMSOL Multiphysics 4.3. The computational domain was discretized by swept mesh and refined until a converged solution was reached. The Direct Solver was applied to solve the transient problem. The Electric Currents module was used to calculate the charge transport in electrodes and electrolyte, and the mass transport was solved by the Transport of Concentrated Species module. The general form of PDEs was employed to calculate the reacted fractions of $\mathrm{Fe}$ and $\mathrm{Fe}_{3} \mathrm{O}_{4}$.

Model validation is of great importance to an accurate numerical analysis and simulation. In this work, the validation process was carried out in three steps: (1) validating the exchange current density of RSOFC by an experimental V-I curve (Fig.4) [28]; (2) determining the reaction rate constant of Fe-oxidization in RCU from JMAK theory by experimental Voltage vs Depth of Discharge (DoD) data collected in the discharge process (Fig.5) [8], (3) determining the reaction rate constant of $\mathrm{Fe}_{3} \mathrm{O}_{4}$-reduction in $\mathrm{RCU}$ from Shrinking Core model by experimental Voltage $v s$ DOD data collected in the charge process (Fig.5) [8].

From Figs. 4 and 5, it is evident that the simulated results agree well with the experimental data; the uncertainty values of voltage predicted from the model with regard to the experimental data are \pm 0.03 and \pm 0.029 volt for the $\mathrm{V}$-I and charge-discharge curves, respectively. The adjustable parameters obtained from fitting the experimental data are marked with “*” in Table 2. Clearly, 
these adjustable parameters are well within reasonable range of their physical meanings, further illustrating the appropriateness of the model. Therefore, the use of these experiment-derived parameters to simulate/predict battery's performance will yield meaningful results. Part II of this paper series present excellent agreement between the experimental data and those predicted by the model. Note that DoD of RCU in the model was converted by integrating the rate of redox reaction in the whole domain with respect to time.

The voltage profiles under $100 \mathrm{~A} \cdot \mathrm{m}^{-2}$ of the discharge and charge cycle is shown in Fig.5 as a function of DOD or Fe utilization. The discharge time for the battery to reach the cutoff voltage $\mathrm{E}_{\text {cutoff }}=0.8$ volt is about 23 hours, corresponding to $\mathrm{DOD}=60 \%$, while the charge time for $\mathrm{E}_{\text {cutoff }}=1.8$ volt is approximately 17 hours, corresponding to $\mathrm{DOD} \approx 45 \%$.

\section{Results and Discussions}

In the following sections, the dynamics of the discharge and charge process of SOIARB will be numerically investigated by the model established above. It is worth mentioning that the overall performance of the system is evaluated by the volume-integration-average method of each parameter.

\subsection{Reaction Kinetics of SOIARB}

The relative magnitude of the kinetic rates of oxidation and reduction reaction occurring in the RCU is critically important to the design and operation of the battery. Ideally, a balanced kinetics of redox reaction is desirable in order to achieve high cycle efficiency and long life cycle. To understand how fast oxidation and kinetics is inside the $\mathrm{Fe}-\mathrm{Fe}_{3} \mathrm{O}_{4}$ couple, we compare the terms 
related to the reacted fraction in eq.(24) for Shrinking Core model and that in eq.(27) for JMAK model, respectively, in Fig.6, as a function of $x_{\mathrm{Fe}} / x_{\mathrm{Fe}_{3} \mathrm{O}_{4}}$. It is evident from the plot that the $x_{\mathrm{Fe}}$ dependent term, $N\left(1-x_{F e}\right)\left[-\ln \left(1-x_{F e}\right)\right]^{1-\frac{1}{N}}$ in JMAK model could be very high, which implicates that the first term in eq.(24) $\left(k_{f} x_{\mathrm{H}_{2} \mathrm{O}}^{4}-k_{b} x_{\mathrm{H}_{2}}^{4}\right)$ can be rather small but still enough to maintain the required current density (oxygen flux density). As $x_{F e}$ increases, the term $N(1-$ $\left.x_{F e}\right)\left[-\ln \left(1-x_{F e}\right)\right]^{1-\frac{1}{N}}$ decreases exponentially, i.e., at $x_{F e}=0.4, N\left(1-x_{F e}\right)[-\ln (1-$ $\left.\left.x_{F e}\right)\right]^{1-\frac{1}{N}}=0.945$ and at $x_{F e}=0.6, N\left(1-x_{F e}\right)\left[-\ln \left(1-x_{F e}\right)\right]^{1-\frac{1}{N}}=0.14$. In general, the Fe oxidation during the discharge cycle requires a relatively small deviation from the equilibrium state (see Section 2.3, $x_{\mathrm{H}_{2} \mathrm{O}}: x_{\mathrm{H}_{2}}=0.21: 0.79$ ) to reach a new dynamic equilibrium with RSOFC. To drive the oxidation reaction, there is 0.79 difference in $x_{\mathrm{H}_{2} \mathrm{O}}$ to vary from 0.21 to 1.00 .

In contrast, Shrinking Core model indicates that $x_{\mathrm{Fe}_{3} \mathrm{O}_{4}}$-dependent term, $\left(1-x_{\mathrm{Fe}_{3} \mathrm{O}_{4}}\right)^{2 / 3}$, only varies from 1 to 0 as $x_{\mathrm{Fe}_{3} \mathrm{O}_{4}}$ is increased from 0 to 1 . A much larger deviation from the equilibrium state is required to reach a new dynamic equilibrium. This is consistent with the reaction (3), which mandates a $x_{H_{2}}>0.79$ in order to drive the reaction to proceed in the backward direction. In this case, there is only 0.21 difference in $x_{\mathrm{H}_{2}}$ (from 0.79 to 1.00 ) in the shuttle gas to drive the reduction cycle, which is clearly a disadvantage compared to the oxidation cycle where there is 0.79 difference in $x_{\mathrm{H}_{2} \mathrm{O}}$ available for the oxidation cycle.

In summary, from the concentration perspective, the oxidation cycle is more advantageous than the reduction cycle. This is in addition to the fact that the intrinsic kinetic rate constant for Fe oxidation is generally higher than that of $\mathrm{Fe}_{3} \mathrm{O}_{4}$ reduction. The combined kinetic limitation has resulted in less chargeable hours and more unreacted $\mathrm{Fe}_{3} \mathrm{O}_{4}$ in the RCU as shown in Fig.5. A 
cyclic accumulation of unreacted $\mathrm{Fe}_{3} \mathrm{O}_{4}$ could lead to a gradual degradation of the battery since less and less $\mathrm{Fe}$ becomes available for subsequent discharge cycle. Therefore, balancing the concentrations between $\mathrm{H}_{2}$ and $\mathrm{H}_{2} \mathrm{O}$ in the oxygen shuttle gas and enhancing the kinetic rate constant of RCU materials are vitally important to achieve high cycle efficiency and long cycle life. Finding new RCU materials that equilibrate with a $\mathrm{H}_{2} / \mathrm{H}_{2} \mathrm{O}=0.5 / 0.5$ can solve the first problem (with compromise in Nernst potential), whereas increasing surface areas of RCU particles and implementation of catalysts can meet the second challenge. Our early study using carbothermic reaction derived Fe-based RCU has proven the latter [8].

\subsection{Electrochemical performance of RSOFC}

The current density profile across the RSOFC is shown in Fig.7. From 0 hour to 23 hour (DOD $=60 \%$ ), RSOFC works under SOFC mode to produce electricity and $\mathrm{H}_{2} \mathrm{O}$; we take the discharge current density as positive. At the 23-hour, the operating mode of RSOFC is switched to electrolysis, which consumes electricity and produces $\mathrm{H}_{2}$; we take the charge current density as negative. The charge cycle lasts for 17 hours ( $\mathrm{DOD}=45 \%)$.

The corresponding current density or mass-flux equivalent current density calculated from the integral of current sources at $\mathrm{H}_{2}$-electrode, as well as converted from the reacted fraction in $\mathrm{Fe}$ $\mathrm{Fe}_{3} \mathrm{O}_{4}$ redox-couple is shown in Fig.8. It is evident that all the oxygen flux (or current) generated by RSOFC is consumed by RCU during the discharge process. Similarly, in the charge process, all the oxygen flux (or current) consumed by RSOFC is matched out by the mass-flux equivalent current generated by RCU. This plot is a good illustration of the dynamic equilibrium between RSOFC and RCU. 
The distributions of electronic potential measured at oxygen electrode, and the calculated overpotential by eq.(8) is shown in Figs. 9 and 10 at different time intervals. To track the variations in distribution, four time intervals are selected: $0 \mathrm{~s}$ (start of discharge), $82700 \mathrm{~s}$ (23h$100 \mathrm{~s}$, end of discharge $), 82900 \mathrm{~s}(23 \mathrm{~h}+100 \mathrm{~s}$, start of charge $), 143900 \mathrm{~s}(23 \mathrm{~h}+17 \mathrm{~h}$, end of charge). Fig. 9 shows the distribution of electronic potential across RSOFC; $\mathrm{H}_{2}$-electrode is considered at $0 \mathrm{~V}$ potential (reference electrode). At the beginning, open-circuit condition, the electronic potential of $\mathrm{O}_{2}$-electrode is as high as $1.14 \mathrm{~V}$, close to the theoretical value with $\mathrm{H}_{2} / \mathrm{H}_{2} \mathrm{O}=0.97 / 0.03$ as a fuel. At $82,700 \mathrm{~s}$, it reduces to $0.8 \mathrm{~V}$, which is resulted from the polarization loss and increase in $\mathrm{H}_{2} \mathrm{O}$ concentration in the fuel caused by the physical change in RCU, i.e., porosity reduction to be shown later. At $82,900 \mathrm{~s}$, where the operating mode is switched to charging, the electronic potential increases to $1.19 \mathrm{~V}$, the difference of which to open-circuit voltage reflects the loss arisen from the polarization in RSOFC. At the end of the discharge process, $143,900 \mathrm{~s}$, the electronic potential of oxygen electrode reaches $1.73 \mathrm{~V}$. Overall, there is virtually no in-plane variation in electronic potentials at all functional layers of RSOFC.

Similarly, Fig.10 shows the distributions of electrode overpotentials at the selected time interval; negative value is for $\mathrm{O}_{2}$-electrode and positive value for $\mathrm{H}_{2}$-electrode. At $0 \mathrm{~s}$, open-circuit condition, the overpotential is negligible, $0.000014 \mathrm{~V}$ for $\mathrm{O}_{2}$-electrode and $0.0004 \mathrm{~V}$ for $\mathrm{H}_{2}-$ electrode. At the $82,700 \mathrm{~s}$, it is $-0.03 \mathrm{~V}$ for the $\mathrm{O}_{2}$-electrode and increases to $0.16 \mathrm{~V}$ for the $\mathrm{H}_{2}$ electrode, suggesting higher polarization loss at $\mathrm{H}_{2}$-electrode than at $\mathrm{O}_{2}$-electrode. At the 82,800 $\mathrm{s}$, the overpotentials of both electrodes become positive after transitioning from fuel-cell to electrolysis operation. At the $143,900 \mathrm{~s}$, the signs of the overpotentials in the two electrodes switched, with overpotential being positive at $\mathrm{O}_{2}$-electrode and negative at $\mathrm{H}_{2}$-electrode. Under 
the same current density, the magnitude of overpotential changes to $0.07 \mathrm{~V}$ and $-0.32 \mathrm{~V}$, respectively, for $\mathrm{O}_{2}$-electrode and $\mathrm{H}_{2}$-electrode. Again, there is virtually no in-plane variation in electronic potentials at all functional layers of RSOFC.

The Nernst potential of RSOFC calculated from eq.(9) is shown in Fig.11. At the very beginning of the discharge cycle, it observes an instant drop from $1.15 \mathrm{~V}\left(\mathrm{OCV}\right.$ with $\left.\mathrm{H}_{2} / \mathrm{H}_{2} \mathrm{O}=0.97 / 0.03\right)$ to 1.06V (OCV with $\mathrm{H}_{2} / \mathrm{H}_{2} \mathrm{O}=0.79 / 0.21$ ). The Nernst potential then gradually decreases to $1.0 \mathrm{~V}$, reflecting a small decrease in $\mathrm{H}_{2}$ concentration. When the operating mode is switched to charging, the Nernst potential instantly jumps to $1.08 \mathrm{~V}$. During the charge cycle, it continues to increase until $1.3 \mathrm{~V}$. The profile of Nernst potential throughout the cycle is closely related to the variation of $\mathrm{H}_{2}$ molar fraction in the $\mathrm{H}_{2}$-electrode/chamber interface.

\subsection{Mass transport in RCU}

The distributions of $x_{\mathrm{H}_{2}}$ at $\mathrm{H}_{2}$-electrode, chamber and $\mathrm{RCU}$ are shown in Fig.12 at the selected time intervals. It is evident that under each time interval, the gradient of $x_{H_{2}}$ is very small, which indicates that diffusion is not a limiting process to reach new dynamic equilibrium. At $0 \mathrm{~s}$, $x_{H_{2}} \approx 0.97$ in the entire domain. At $82,700 \mathrm{~s}$, the end of discharge, it is decreased greatly to 0.43 . After the immediate switch to the charge cycle at $82,900 \mathrm{~s}, x_{\mathrm{H}_{2}}$ returns 0.87 . At $143,900 \mathrm{~s}$, it becomes one, which implies that there is no $\mathrm{H}_{2} \mathrm{O}$ in the fuel chamber for RSOFC to electrolyze; the charge cycle cannot be sustained.

To further understand the variations of $x_{\mathrm{H}_{2}}$ and $x_{\mathrm{H}_{2} \mathrm{O}}$ in RCU, we integrated and averaged them by volume; the results are shown in Fig.13. For $\mathrm{H}_{2}$, there is an instant step change at the very beginning of the discharge process, which arises from the fact that RSOFC and RCU are not in a dynamic equilibrium during this short transient period. As $x_{H_{2}}$ reaches 0.79 , it remains stable for 
up to 10 hours, after which it starts to decrease with time. At 23 hour, RSOFC is switched to electrolysis mode, $x_{\mathrm{H}_{2}}$ instantly increases to $\sim 0.9$, which also implies that the reduction of $\mathrm{Fe}_{3} \mathrm{O}_{4}$ needs a greater driving force than the Fe-oxidization. After an initial stabilization, $x_{\mathrm{H}_{2}}$ begins to gradually increase towards 1 where the cutoff voltage is reached. The variation of $x_{\mathrm{H}_{2} \mathrm{O}}$ is complementary to that of $x_{\mathrm{H}_{2}}$. It is to be noted that this profile is closely related to the Nernst potential shown in Fig.11.

The Depth of Discharge (DOD) of RCU is converted from the current generated and consumed in this study and is shown in Fig.14. It is also equivalent to the Fe utilization. From 0 to 23 hour, DOD linearly increases from 0 to 0.6 , the slop of which is proportional to the current density applied to RSOFC. Similarly, DOD decreases to 0.15 at the end of the charge cycle, which means $15 \%$ unreduced $\mathrm{Fe}_{3} \mathrm{O}_{4}$ in the RCU. At this point, the charge process could not be maintained due to the depletion of $\mathrm{H}_{2} \mathrm{O}$ in the fuel chamber.

As the molar volumes of $\mathrm{Fe}$ and $\mathrm{Fe}_{3} \mathrm{O}_{4}$ are different, the porosity of $\mathrm{RCU}$ will change with DOD;

this is shown in Fig.15. Recall eq.(28), the term $\left(\frac{M_{F e}}{\rho_{F e}}-\frac{1}{3} \frac{M_{F_{3} O_{4}}}{\rho_{F_{3} O_{4}}}\right)$ is negative; therefore, the volume-averaged porosity of RCU decreases with DOD ( $\sim .475$ at the end of discharge cycle). Conversely, for the charge cycle, the reduction of $\mathrm{Fe}_{3} \mathrm{O}_{4}$ leads to an increase in porosity. The slop of the curve is related to the current density applied, which is constant.

\section{Conclusions}

In this study, a high-fidelity 2D axial symmetrical multi-physics model has been developed for a novel solid oxide metal-air redox battery system with a Fe-based redox cycle unit of energy 
storage. The model integrates mass transport and charge transfer with chemical redox cycle kinetics occurring in all components of the battery, the parameters of which were directly validated by independent experimental data. Understanding the rate-limiting steps of the battery was the primary focus of this study. The results indicate that the oxygen shuttle gas $\mathrm{H}_{2}-\mathrm{H}_{2} \mathrm{O}$ is very effective in transporting oxygen between RSOFC and RCU. It is the reduction kinetics in the RCU that limits the performance of the battery. The oxidation kinetics is much faster than that of reduction, making the discharge cycle easier to maintain than the charge cycle. Finally, the distributions of electrode potential, overpotential, Nernst potential, molar fractions of $\mathrm{H}_{2}$ and $\mathrm{H}_{2} \mathrm{O}$ across the components of the battery are shown to vary in the axial direction but remain fairly uniform in the radial direction (in-plane).

In the second part of this paper series, we will demonstrate the results of a systematic parametric study and performance optimization strategies based on the model established herein.

\section{Acknowledgements}

The information, data or work presented herein was funded in part by the Advanced Research Projects Agency-Energy (ARPA-E), U.S. Department of Energy, under Award number DEAR0000492.

\section{References}

[1] N.S. Xu, X. Li, X. Zhao, J.B. Goodenough, K. Huang, Energ Environ Sci, 4 (2011) $4942-$ 4946. 
[2] X. Zhao, N.S. Xu, X. Li, Y.H. Gong, K. Huang, Rsc Adv, 2 (2012) 10163-10166.

[3] X. Zhao, N. Xu, X. Li, Y. Gong, K. Huang, ECS Transactions, 50 (2013) 115-123.

[4] X. Zhao, X. Li, Y. Gong, N. Xu, K. Huang, ECS Transactions, 58 (2014) 67-74.

[5] X. Zhao, N. Xu, X. Li, Y. Gong, K. Huang, ECS Transactions, 45 (2013) 113-121.

[6] X. Zhao, X. Li, Y.H. Gong, N.S. Xu, K. Romito, K. Huang, Chemical Communications, 49 (2013) 5357-5359.

[7] X. Zhao, Y.H. Gong, X. Li, N.S. Xu, K. Huang, J Mater Chem A, 1 (2013) 14858-14861.

[8] X. Zhao, X. Li, Y. Gong, K. Huang, Chemical Communications, (2014) 623-625.

[9] X. Zhao, Y.H. Gong, X. Li, N.S. Xu, K. Huang, J Electrochem Soc, 160 (2013) A1716A1719.

[10] X. Zhao, Y.H. Gong, X. Li, N.S. Xu, K. Huang, J Electrochem Soc, 160 (2013) A1241A1247.

[11] H. Ohmori, S. Uratani, H. Iwai, J Power Sources, 208 (2012) 383-390.

[12] H. Ohmori, H. Iwai, ECS Transactions, 57 (2013) 233-242.

[13] M. Guo, X. Zhao, R.E. White, K. Huang, J Electrochem Soc, 160 (2013) A2085-A2092.

[14] Y.X. Shi, N.S. Cai, C. Li, J Power Sources, 164 (2007) 639-648.

[15] W.G. Bessler, S. Gewies, M. Vogler, Electrochim Acta, 53 (2007) 1782-1800.

[16] W.D. He, J. Zou, B. Wang, S. Vilayurganapathy, M. Zhou, X. Lin, K.H.L. Zhang, J.H. Lin, P. Xu, J.H. Dickerson, J Power Sources, 237 (2013) 64-73. 
[17] E.R. Fotsing, in, Fakultät für Bergbau, Hüttenwesen und Maschinenwesen of the Technische Universität Clausthal, 2005, pp. 141.

[18] J. Torrens-Serra, S. Venkataraman, M. Stoica, U. Kuehn, S. Roth, J. Eckert, Materials, 4 (2011) 2231-2243.

[19] Advances in Crystallization Processes, InTech, 2012.

[20] E. Lorente, J.A. Pena, J. Herguido, Int J Hydrogen Energ, 33 (2008) 615-626.

[21] S. Noorman, F. Gallucci, M.V. Annaland, J.A.M. Kuipers, Chem Eng J, 167 (2011) 297307.

[22] M. Thaler, V. Hacker, Int J Hydrogen Energ, 37 (2012) 2800-2806.

[23] J.A. Pena, E. Lorente, E. Romero, J. Herguido, Catal Today, 116 (2006) 439-444.

[24] M.E. Davis, R.J. Davis, Fundamentals of Chemical Reaction Engineering, McGraw-Hill Higher Education, New York, 2003.

[25] L.G.V. Vargas, in: Chemical Engineering, The Ohio State University, 2007.

[26] O. Levenspiel, Chemical Reaction Engineering, John Wiley \& Sons, New York, 1999.

[27] J.C. Maya, F. Chejne, Energy \& Fuels, 28 (2014) 5434-5444.

[28] X. Zhao, thesis in: Mechanical Engineering, University of South Carolina, 2013. 


\section{Nomenclature}

\begin{tabular}{|c|c|}
\hline $\mathrm{c},\left(\mathrm{mol} \cdot \mathrm{m}^{-3}\right)$ & Molar concentration \\
\hline$d_{\text {pore }},(\mathrm{m})$ & Diameter of spherical particle of the porous medium \\
\hline$d_{p},(m)$ & Pore radius of the porous medium \\
\hline$D_{i j},\left(m^{2} \cdot s^{-1}\right)$ & Binary diffusion coefficient for a pair of species $i$ and $j$ \\
\hline $\mathrm{D}_{\mathrm{kn}}, \mathrm{i},\left(\mathrm{m}^{2} \cdot \mathrm{s}^{-1}\right)$ & Knudsen diffusion coefficient of species i \\
\hline $\mathrm{E},(\mathrm{V})$ & Nernst potential \\
\hline $\mathrm{F},\left(\mathrm{C} \cdot \mathrm{mol}^{-1}\right)$ & Faraday's constant, 96485 \\
\hline $\mathrm{G},\left(\mathrm{J} \cdot \mathrm{mol}^{-1}\right)$ & Gibbs free energy \\
\hline $\mathrm{K}$ & Equilibrium constant \\
\hline $\mathrm{k},\left(\mathrm{m}^{2} \cdot \mathrm{s}^{-1}\right)$ & Reference diffusivity \\
\hline$k_{o},\left(\mathrm{~s}^{-1}\right)$ & Global oxidation rate constant \\
\hline$k_{f},\left(\mathrm{~m} \cdot \mathrm{s}^{-1}, \mathrm{~s}^{-1}\right)$ & Forward reaction constant \\
\hline$k_{b},\left(\mathrm{~m} \cdot \mathrm{s}^{-1}, \mathrm{~s}^{-1}\right)$ & Backward reaction constant \\
\hline $\mathrm{M}_{\mathrm{i}},\left(\mathrm{kg} \cdot \mathrm{mol}^{-1}\right)$ & Molar weight of species i \\
\hline $\mathrm{N}_{\mathrm{i}},(\mathrm{mol})$ & Molar of species i \\
\hline $\mathrm{N}$ & Avrami exponent \\
\hline $\mathrm{i}_{\mathrm{ict}},\left(\mathrm{A} \cdot \mathrm{m}^{-2}\right)$ & Local charge transfer current density \\
\hline $\mathrm{p},(\mathrm{Pa})$ & Pressure \\
\hline $\mathrm{R},\left(\mathrm{J} \cdot\left(\mathrm{mol}^{-1} \cdot \mathrm{K}^{-1}\right)\right)$ & Gas constant, 8.314 \\
\hline $\mathrm{R}_{\mathrm{c} 0},(\mathrm{~m})$ & Initial radius of core \\
\hline $\mathrm{r},\left(\mathrm{mol} \cdot \mathrm{m}^{-3} \cdot \mathrm{s}^{-1}\right)$ & Reaction rate \\
\hline$r_{c},(\mathrm{~m})$ & Radius of the core in the shrinking core model \\
\hline $\mathrm{R}_{\mathrm{i}},\left(\mathrm{kg} \cdot \mathrm{m}^{-3} \cdot \mathrm{s}^{-1}\right)$ & Reaction source term for species i \\
\hline $\mathrm{Sa},\left(\mathrm{m}^{-1}\right)$ & Electrochemical reaction active area per unit volume \\
\hline $\mathrm{T},(\mathrm{K})$ & Temperature \\
\hline $\mathrm{t},(\mathrm{s})$ & Time \\
\hline $\mathrm{x}_{\mathrm{j}}$ & Molar fraction of species $\mathrm{j}$ \\
\hline
\end{tabular}

\section{Greek symbols}




$\begin{array}{ll}\sigma,\left(\mathrm{S} \cdot \mathrm{m}^{-1}\right) & \text { Conductivity } \\ \phi,(\mathrm{V}) & \text { Potential } \\ \eta,(\mathrm{V}) & \text { Overpotential } \\ \rho,\left(\mathrm{kg} \cdot \mathrm{m}^{-3}, \mathrm{~mol} \cdot \mathrm{m}^{-3}\right) & \text { Density } \\ \omega_{\mathrm{i} / \mathrm{j}} & \text { Mass fraction of species } \mathrm{i} / \mathrm{j} \\ \mathrm{v}_{\mathrm{i}} & \text { Kinetic volume of species } \mathrm{i} \\ \varepsilon & \text { Porosity } \\ \tau & \text { Tortuosity }\end{array}$

\section{Subscripts}

e

eff

el

eq

i

g

o

h

react

prod

\section{Superscripts}

0
Electronic

Effective

Electrolyte

Equilibrium

Ionic

Gas

Oxygen electrode

Hydrogen electrode

Reactant

Product

Ideal/Initial 
Table 1 Boundary conditions

\begin{tabular}{|c|c|c|c|}
\hline Boundary & Electronic potential & Ionic potential & $\begin{array}{c}\text { Stefan-Maxwell } \\
\text { diffusion }\end{array}$ \\
\hline Air $/ \mathrm{O}_{2}$ electrode & $\phi_{\mathrm{c}}$ & N/A & $\begin{array}{c}\mathrm{O}_{2}: \mathrm{N}_{2}: \mathrm{H}_{2} \mathrm{O} \\
0.21: 0.03: 0.76\end{array}$ \\
\hline $\begin{array}{c}\mathrm{O}_{2} \text {-electrode/electrolyte } \\
\text { interface }\end{array}$ & N/A & Insulation: $n \cdot J=0$ & $n \cdot J=0$ \\
\hline $\begin{array}{c}\text { electrolyte/} / \mathbf{H}_{2} \text {-electrode } \\
\text { interface }\end{array}$ & $0 \mathrm{~V}$ & Insulation: $n \cdot J=0$ & $n \cdot J=0$ \\
\hline $\mathrm{H}_{2}$ electrode/Chamber & N/A & N/A & Interior boundary \\
\hline Chamber/RCU & N/A & N/A & Interior boundary \\
\hline Other surfaces & $\begin{array}{c}\text { Symmetry/Insulation } \\
n \cdot J=0\end{array}$ & $\begin{array}{c}\text { Symmetry/Insulation } \\
n \cdot J=0\end{array}$ & $\begin{array}{c}\text { Symmetry/Insulation } \\
n \cdot J=0\end{array}$ \\
\hline
\end{tabular}


Table 2 Parameters used in the model

\begin{tabular}{lc}
\hline Parameters & Values \\
Atmospheric pressure, $\mathrm{P}_{0}$ & $1[\mathrm{~atm}]$ \\
Temperature, $\mathrm{T}_{0}$ & $550\left[{ }^{\circ} \mathrm{C}\right]$ \\
Inlet molar fraction of $\mathrm{H}_{2} \mathrm{X}_{\mathrm{ref}, \mathrm{H} 2}$ & 0.97 \\
Inlet molar fraction of $\mathrm{O}_{2} \mathrm{X}_{\mathrm{ref}, \mathrm{O} 2}$ & 0.21 \\
Tortuosity, Anode/Cathode $\tau^{*}$ & 3 \\
Porosity, Anode/Cathode $\varepsilon$ & $0.4 / 0.3$ \\
Electronic conductivity, $\sigma_{\mathrm{e}}$ & $2 \times 10^{6}\left[\mathrm{~S} \cdot \mathrm{m}^{-1}\right]$ \\
Ionic conductivity, $\sigma_{\mathrm{i}, \mathrm{e}}{ }^{*}$ & $1.15\left[\mathrm{~S} \cdot \mathrm{m}^{-1}\right]$ \\
Exchange current, Anode/Cathode $\mathrm{i}_{0} *$ & $75 / 15\left[\mathrm{~A} \cdot \mathrm{m}^{-2}\right]$ \\
Specific surface area, Anode/Cathode $\mathrm{S}_{\mathrm{a}}{ }^{*}$ & $\left(1-\varepsilon_{\mathrm{a} / \mathrm{c}}\right) \times 1.43 \times 10^{5}\left[\mathrm{~m}^{-1}\right]$ \\
Loading of Iron, $\mathrm{m}_{\mathrm{Fe}}$ & $0.26[\mathrm{~g}]$ \\
Initial porosity of RCU, $\varepsilon$ & 0.7 \\
Reaction rate constant of JMAK, $\mathrm{k}_{\mathrm{f}} / \mathrm{k}_{\mathrm{b}}{ }^{*}$ & $10 \times 4.7 \times 10^{-5} / 0.0538 \times 4.7 \times 10^{-5}\left[\mathrm{~s}^{-1}\right]$ \\
\hline $\begin{array}{l}\text { Reaction rate constant of shrinking core } \\
\text { model, } \mathrm{k}_{\mathrm{f}} / \mathrm{k}_{\mathrm{b}} *\end{array}$ & $10 \times 3.83 \times 10^{-7} / 0.0538 \times 3.83 \times 10^{-7}\left[\mathrm{~m}^{-1} \cdot \mathrm{s}^{-1}\right]$ \\
Diameter of spherical particle, \\
Anode/Cathode, $\mathrm{d}_{\mathrm{p}}$
\end{tabular}

Note: The parameters with $*$ are adjusted in order to validate the model with the experimental results. 


\section{Figure Caption}

Fig. 1 A schematic illustration of the SOIARB configuration

Fig. 2 Schematic of the Shrinking Core model

Fig. 3 Finite Element Method (FEM) model of SOIARB (unit: mm)

Fig. 4 Validation of V-I curve under $550^{\circ} \mathrm{C}$

Fig. 5 Validation of E vs DOD (UFe: Fe utilization) curve

Fig. 6 Comparison of reaction kinetics of JMAK and Shrinking Core models

Fig. 7 Current density applied on RSOFC

Fig. 8 Current density in RSOFC and mas-flux equivalent current density in RCU calculated from volume-integration-average approach

Fig. 9 Electric potential distribution at 0, 82700, 82900 and 143900 seconds

Fig. 10 Overpotential distribution at 0, 82700, 82900 and 143900 seconds

Fig. 11 Profile of Nernst potential of RSOFC during a discharge/charge cycle

Fig. 12 Distributions of $\mathrm{H}_{2}$ molar fraction across the battery at $0,82,700,82,900$ and 143,900 seconds, respectively

Fig. 13 Volume averaged molar fractions of $\mathrm{H}_{2}$ and $\mathrm{H}_{2} \mathrm{O}$ in $\mathrm{RCU}$

Fig. 14 Volume averaged Depth of Discharge (DOD) of RCU

Fig. 15 Volume averaged porosity of RCU 


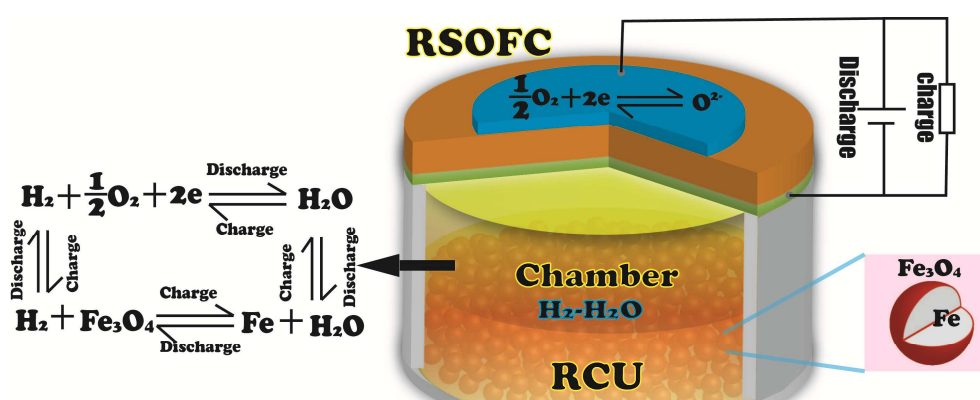

Fig.1

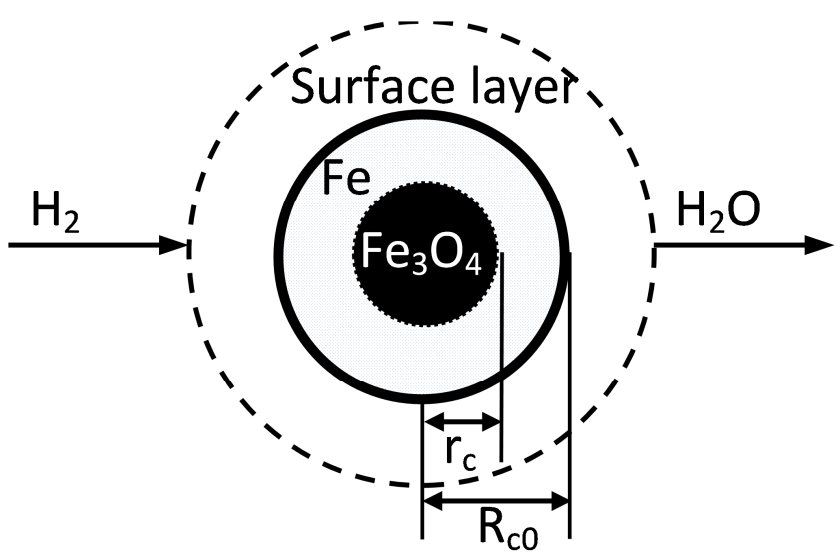

Fig.2 


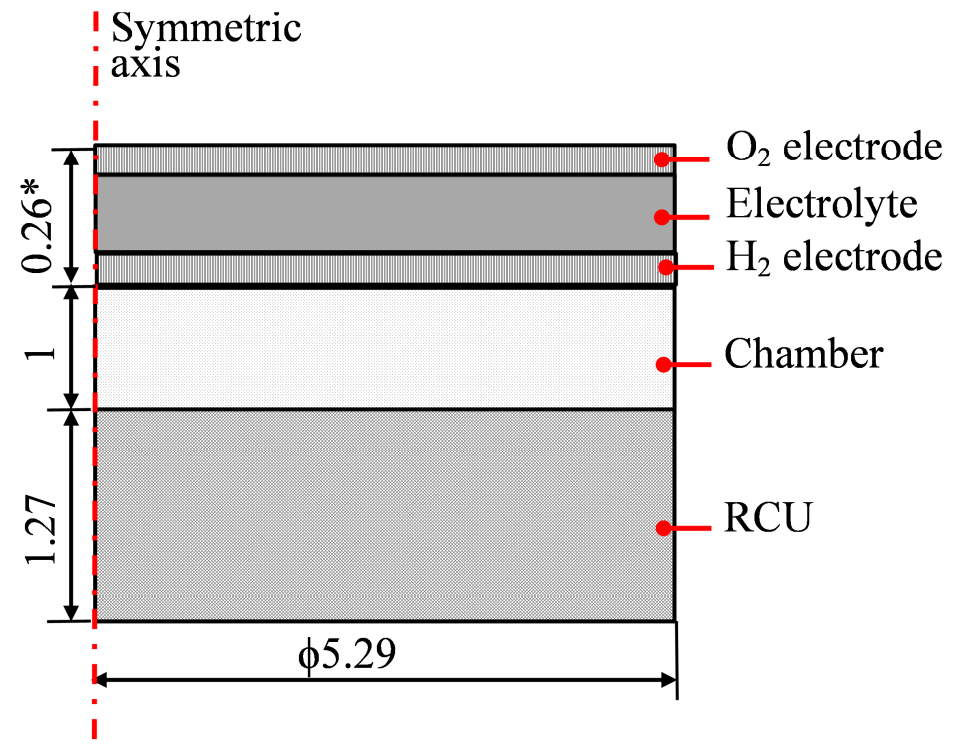

Fig. 3

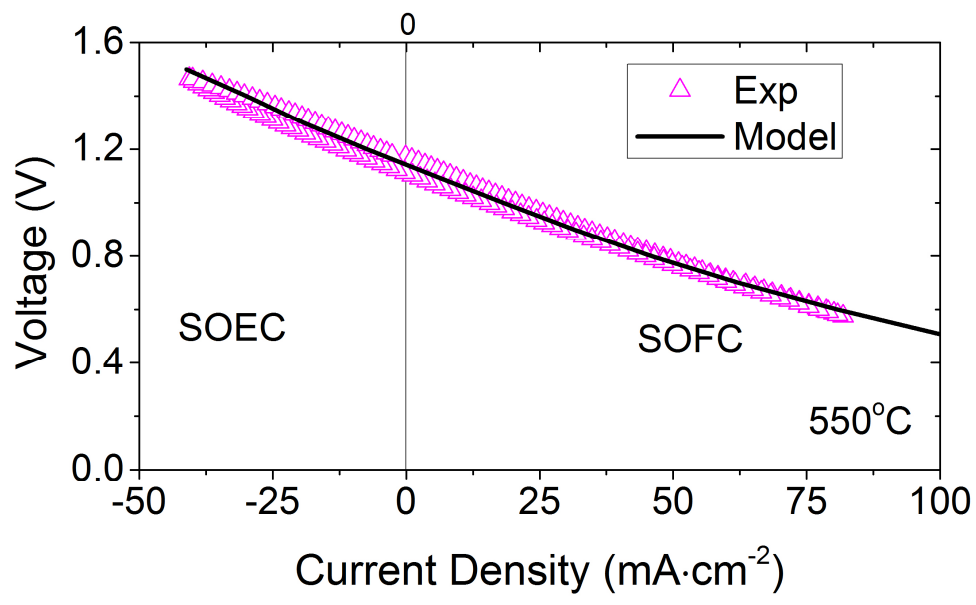

Fig.4 


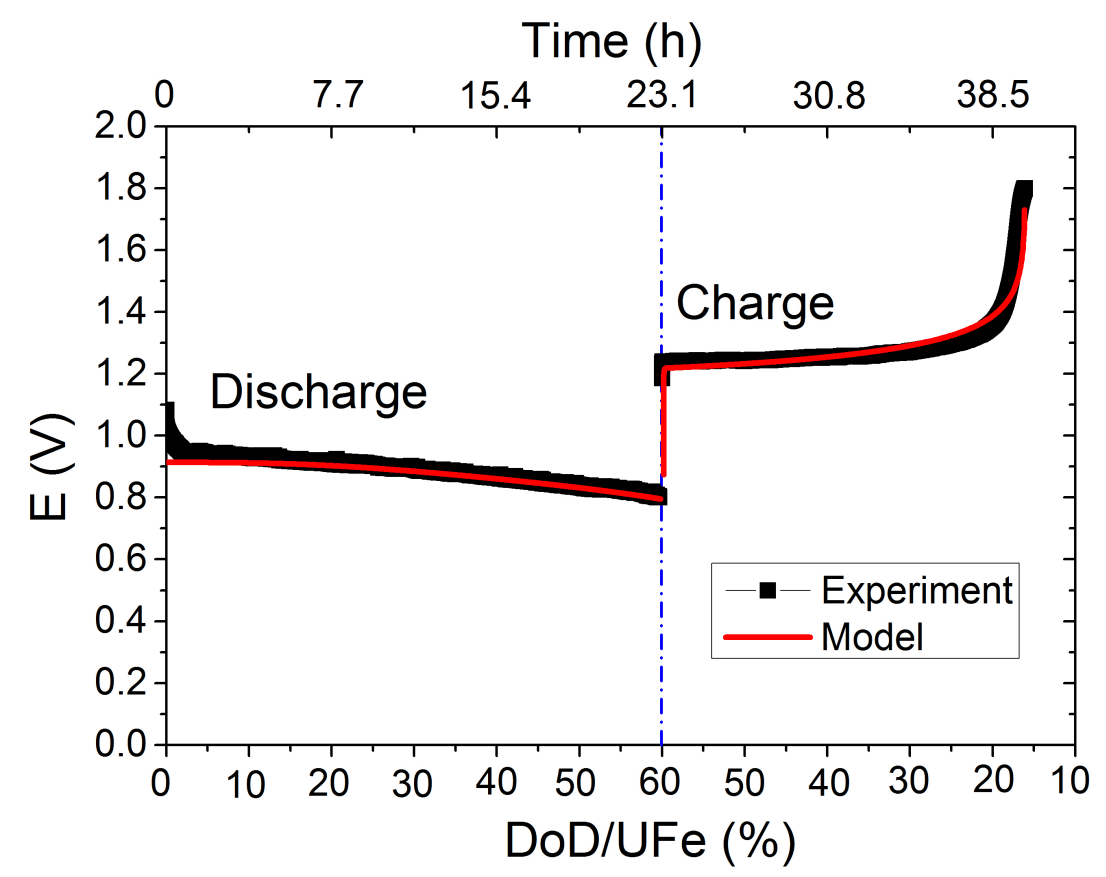

Fig.5

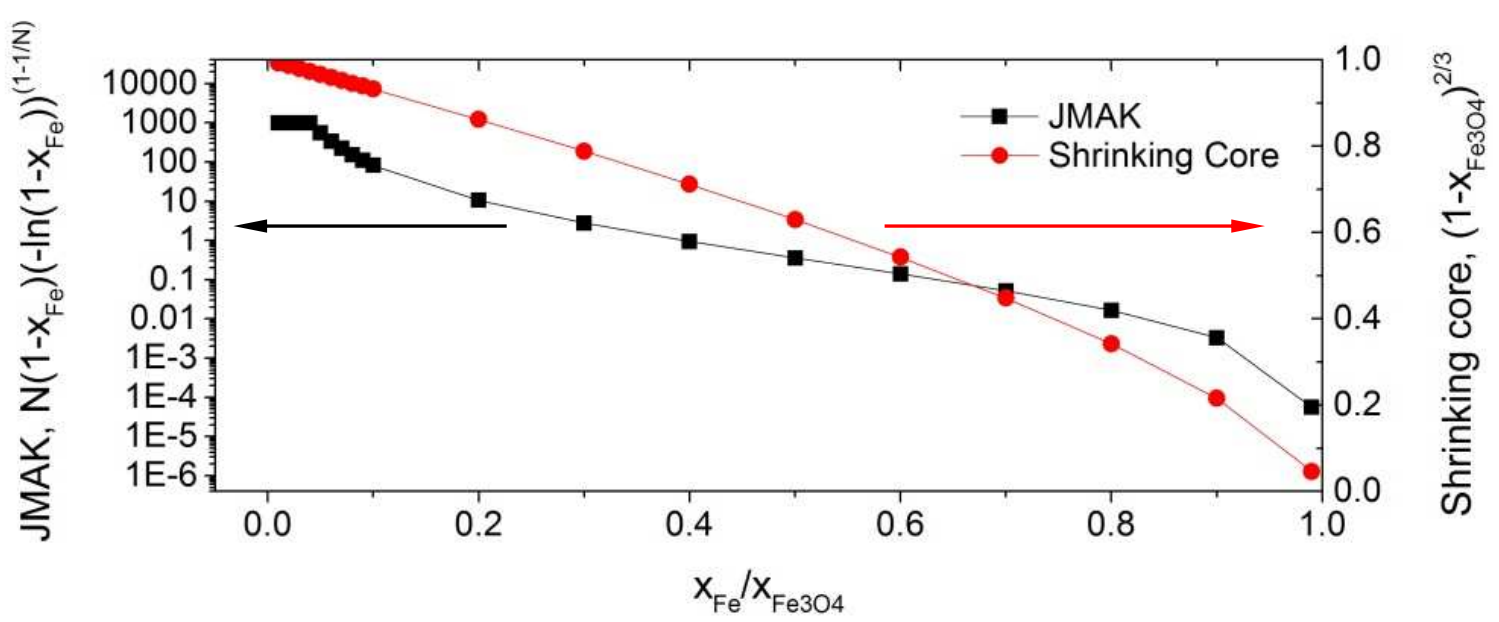

Fig.6 


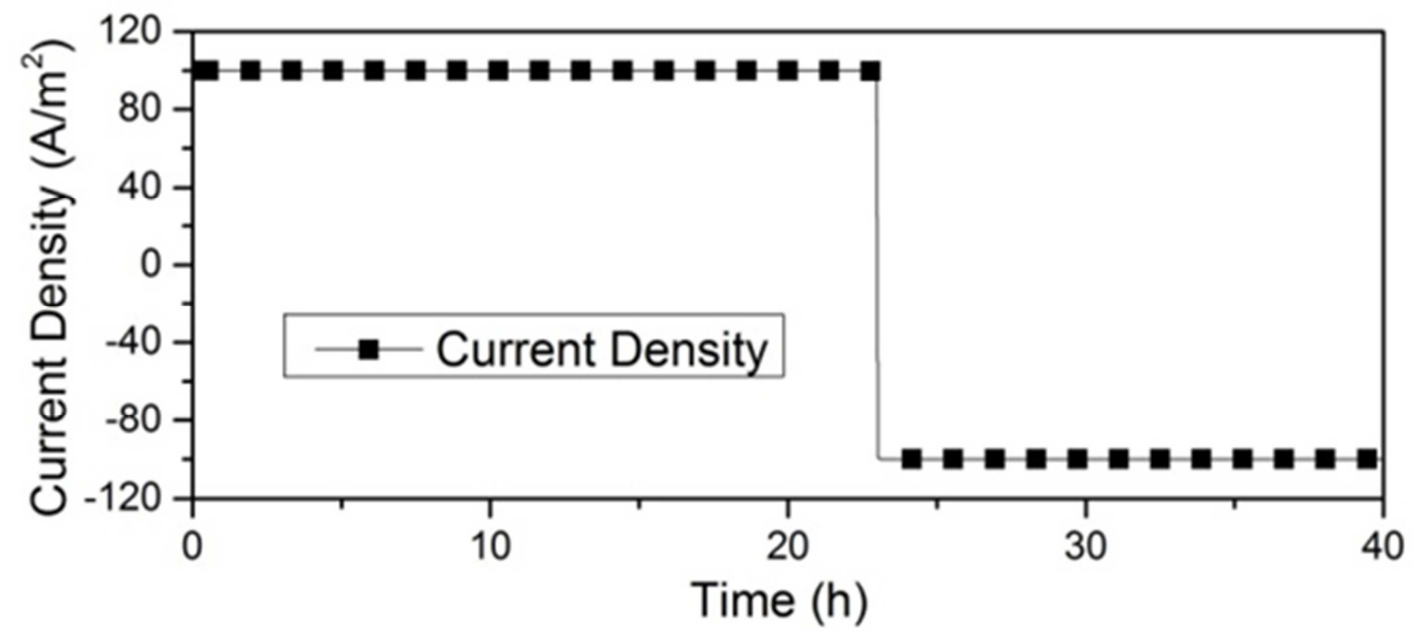

Fig.7

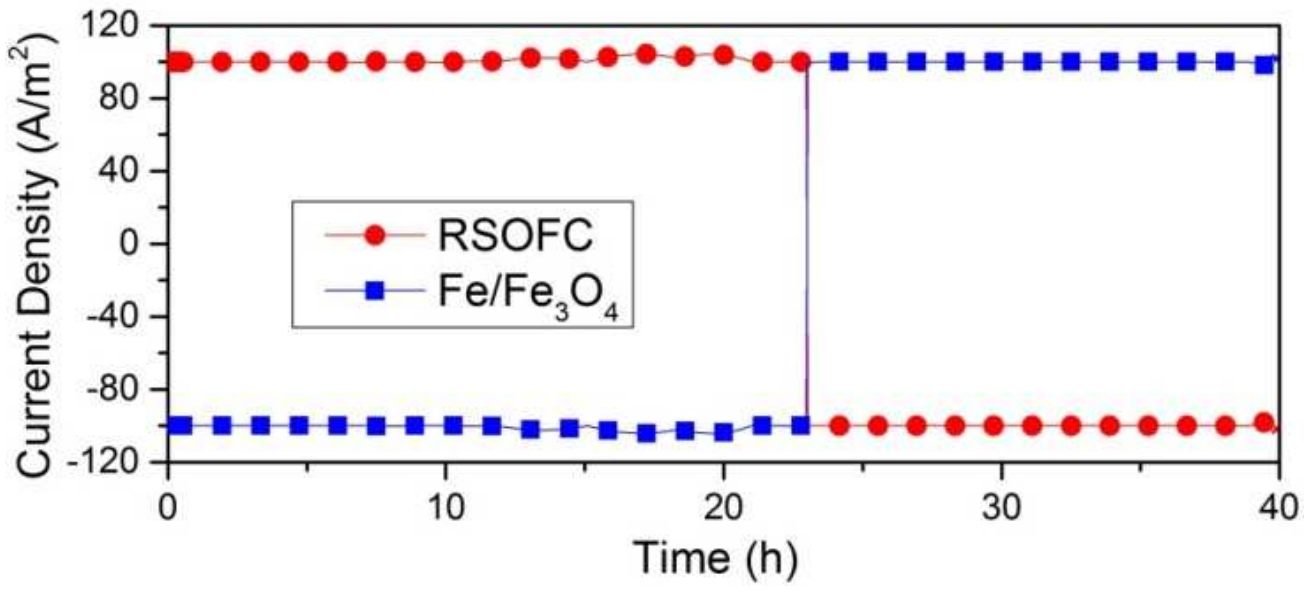

Fig.8 
Electronic

Time $=0 \mathrm{~s}$

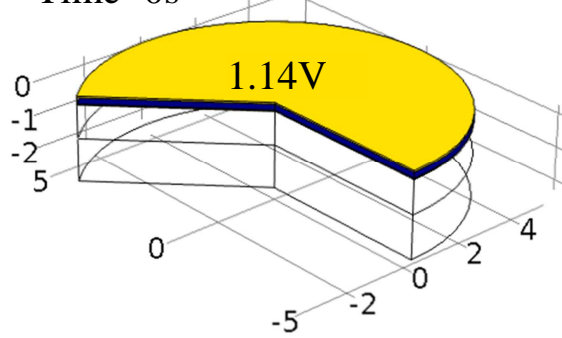

Time $=82700 \mathrm{~s}$

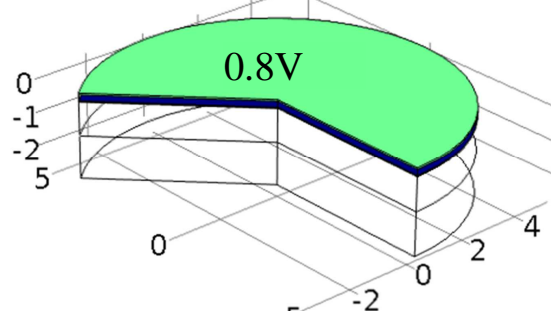

Time $=82900 \mathrm{~s}$

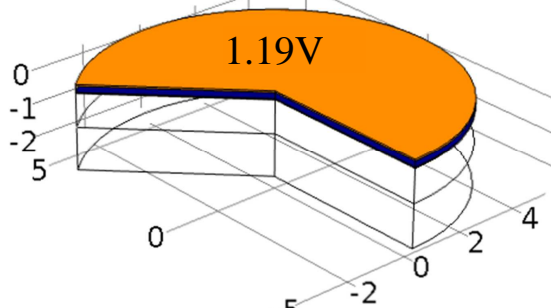

Time $=143900 \mathrm{~s}^{-5}$
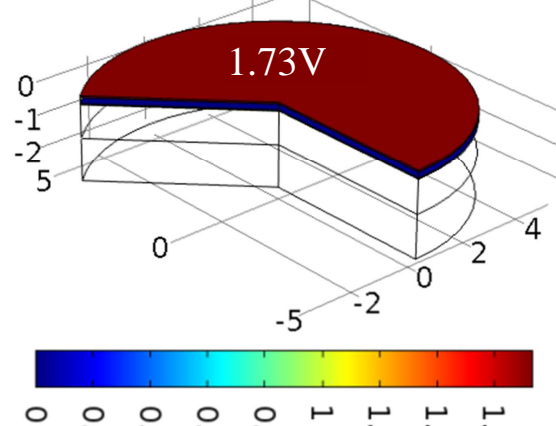

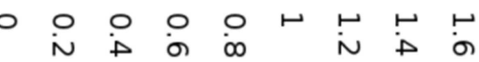

\section{Overpotential}

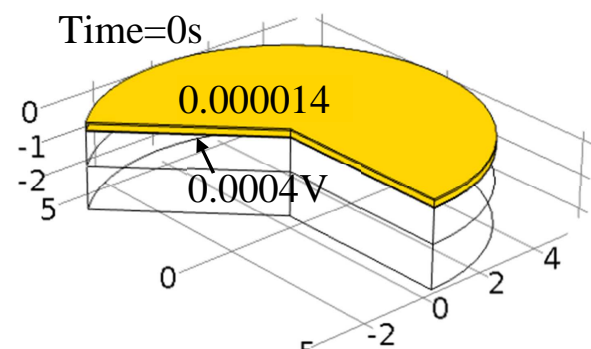

Time $=82700 \mathrm{~s}^{-5}$

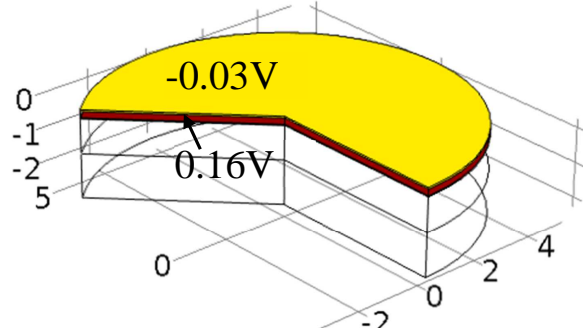

Time $=82900 \mathrm{~s}^{-5}$
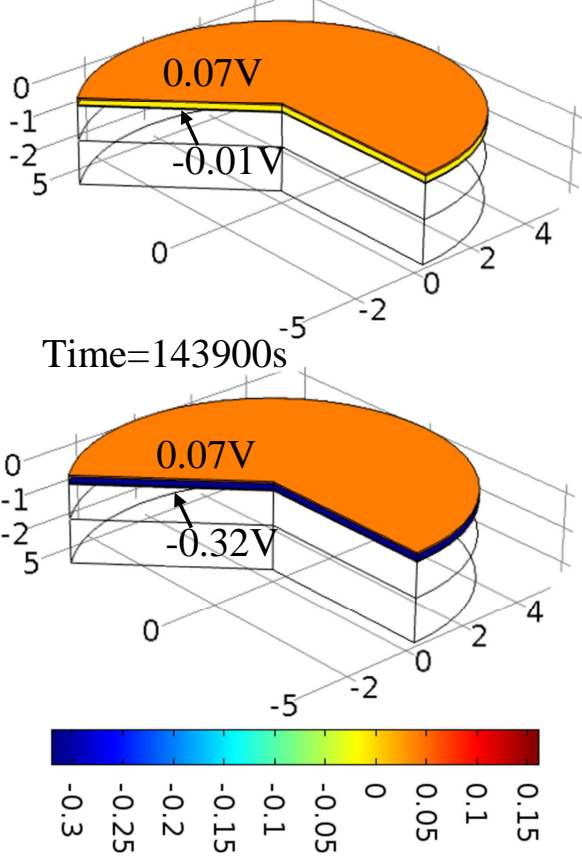

Fig.9

Fig.10 


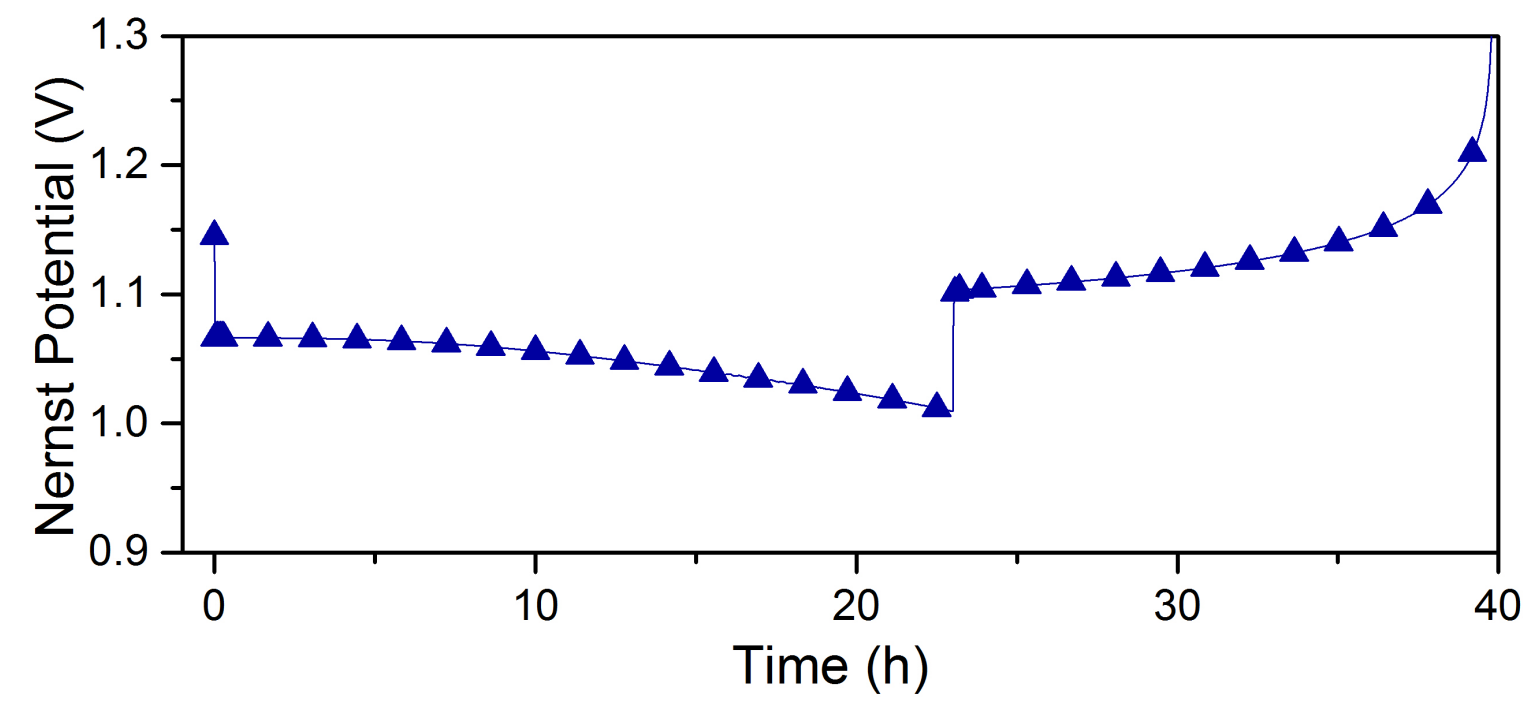

Fig.11 


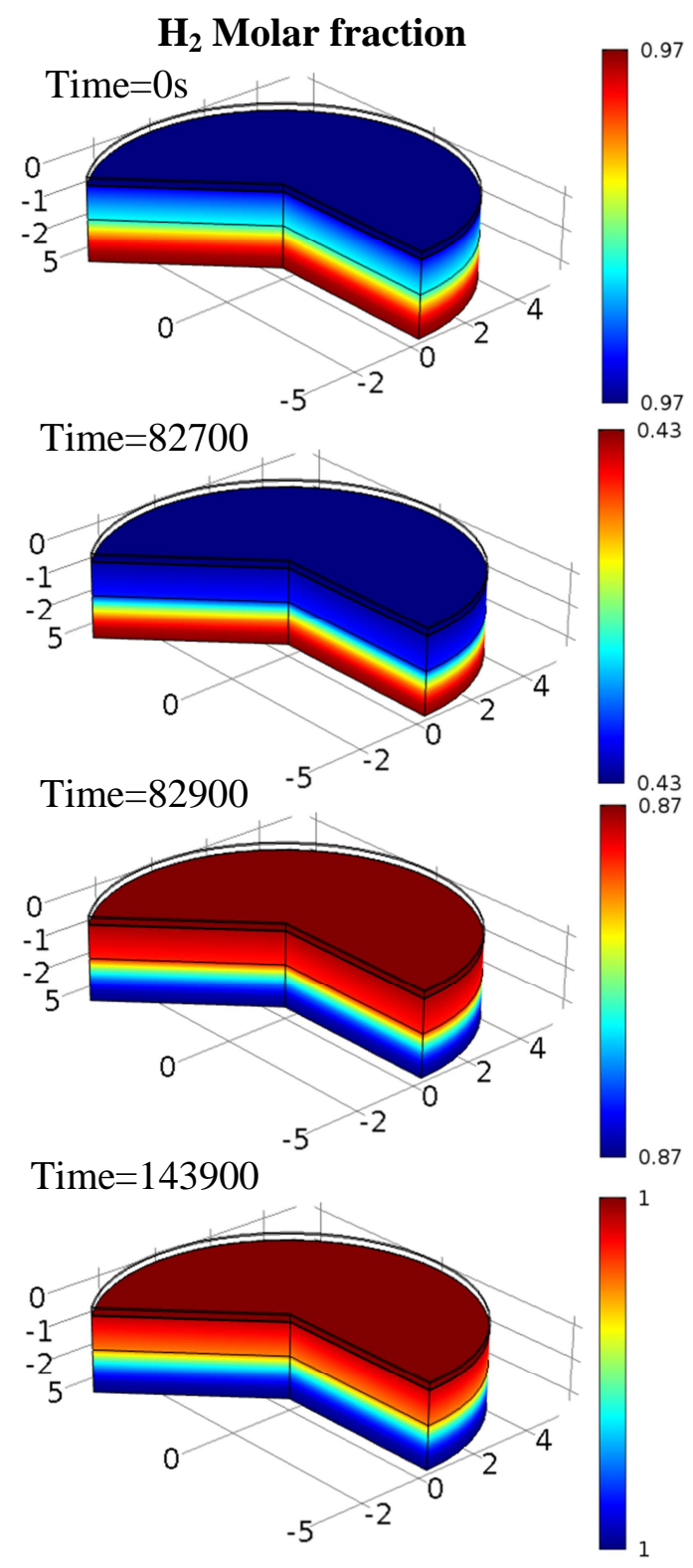

Fig.12 


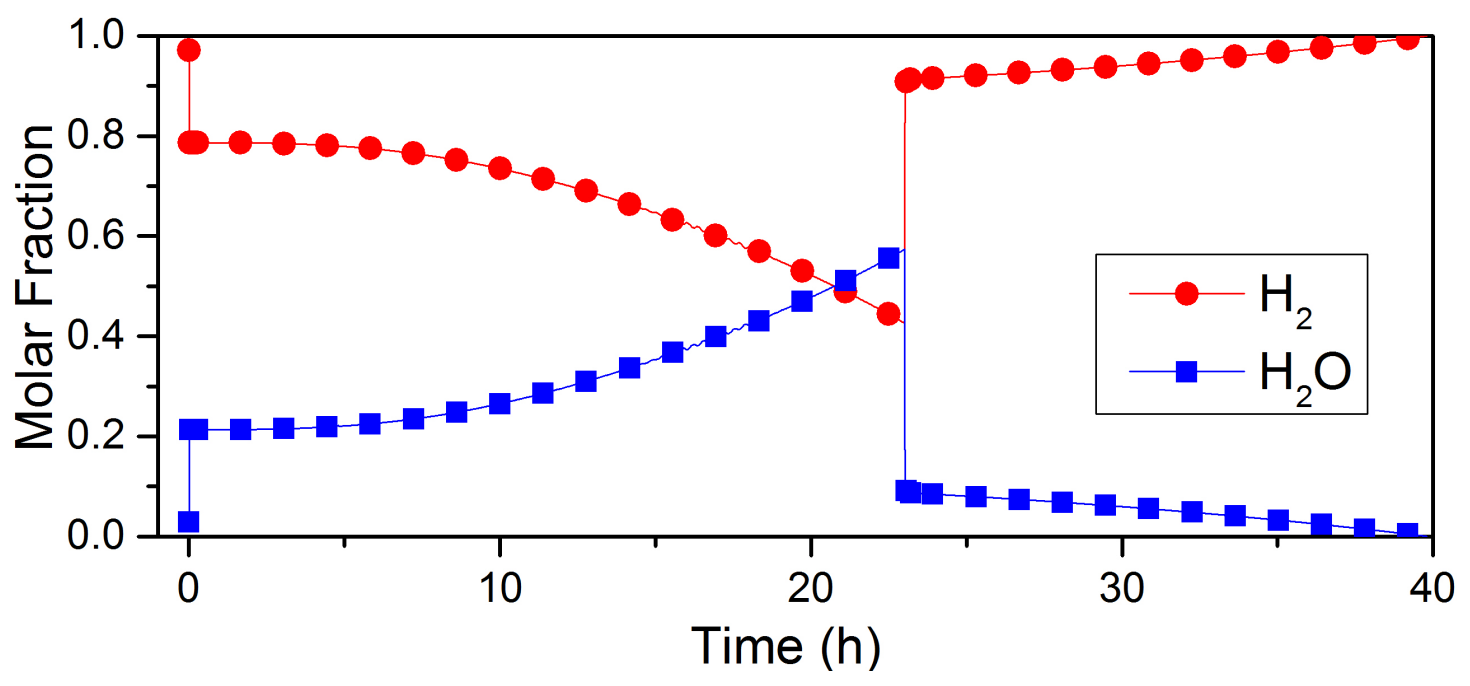

Fig.13

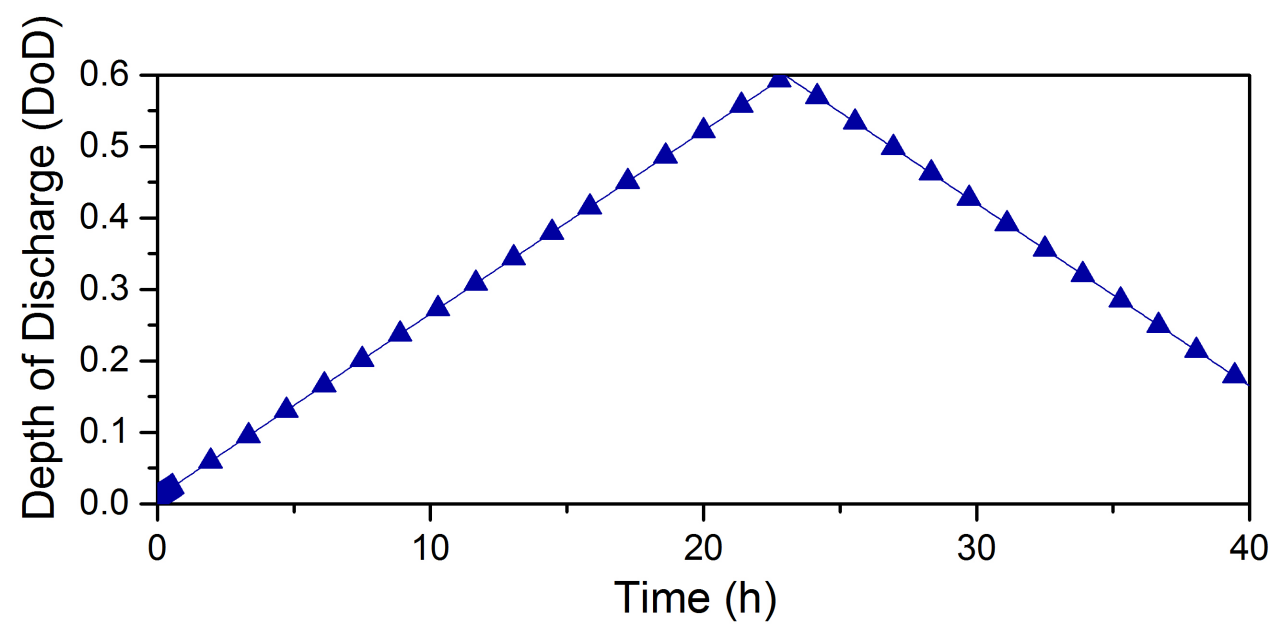

Fig.14 


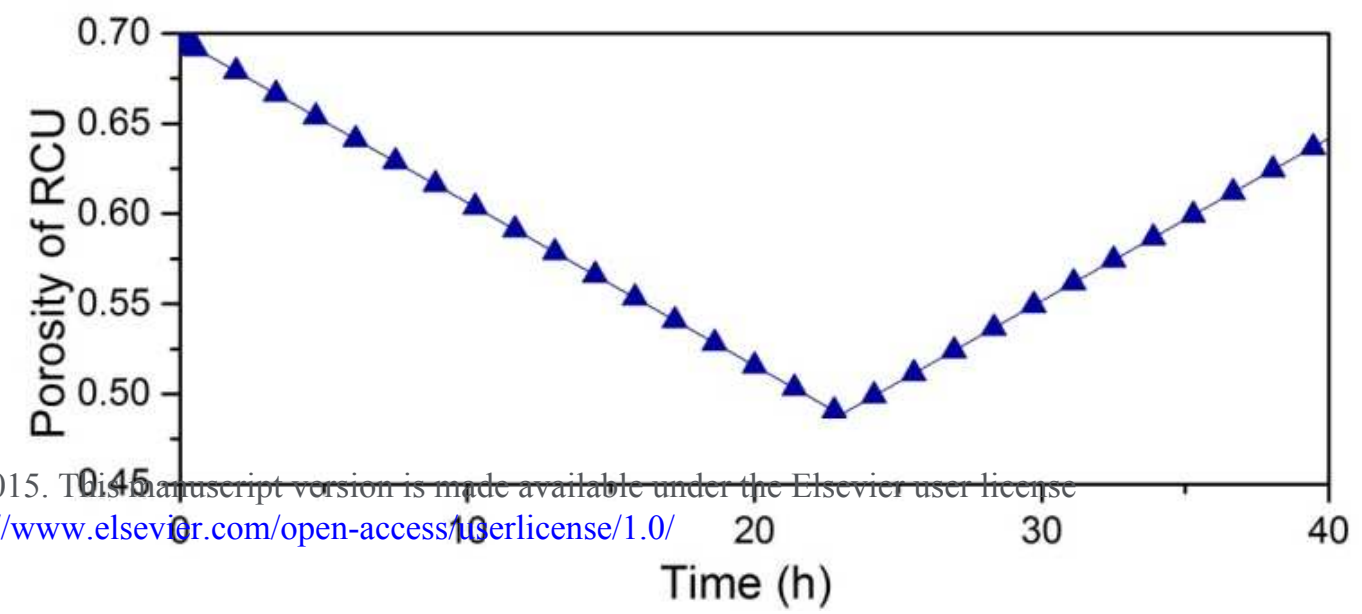

Fig.15 